Birds of the Antarctic and Sub-Antarctic, by George E. Watson in collaboration with J. Phillip Angle and Peter C. Harper, illustrated by Bob Hines. William Byrd Press, Richmond, Virginia, \$15.

The Bird Man by Ian Strange. Gordon and Cremonesi, $£ 6.90$.

Dr Watson's contribution to the Antarctic Research Series is much more than an identification guide, though it fills that purpose admirably. A pocket-sized handbook of 350 pages, it includes a sixty-page introduction describing the antarctic and sub-antarctic environments in a general, way and a geographical section discussing each major land area individually. (A few areas, e.g. the Falkland Islands, are omitted as they have been covered by other publications.) It is packed with aids to identification and information on the birds' biology and distribution - as well as indications of gaps in our present knowledge that need to be filled. There are most useful illustrations in black and white and in colour, together with distribution maps and tables. Any ornithologist visiting these regions, whether expert or amateur, would want the book in his pocket.

In contrast Mr Strange's volume is no scientific handbook: it is a love story. Devoted from childhood to birds and mammals, he had little or no scientific training and simply picked up his knowledge in the field, as an East Anglian farmer. In 1959 he accepted the job of starting a mink farm in the Falkland Islands, where he became captivated by the wildlife and obsessed with the problem of its conservation. He quickly realised both the damage which had already been done and the need for nature reserves if important bird and seal colonies were to survive. Government officials were apparently unsympathetic and indeed uninterested, while he, for his part, had no notion of how to tackle officialdom. He explains that he had to tread on many toes. No doubt the authorities at first thought him to be merely a tiresome and unqualified crank - after all, he had no $\mathrm{PhD}$ after his name! In the end he won through by sheer, stubborn persistence but only at the cost of repeated disappointments and much hardship and danger. For nearly 20 years his life was dominated by the passionate promotion of his cause, and this book is the story of his struggles. Eventually, with international support (notably that of the FPS) a considerable measure of success was achieved, and some thirty islands and 'mainland' areas have now been designated as reserves or sanctuaries. (Incidentally, I must contradict his statement that I opposed a WWF proposal for national parks in the Ecuadorean Andes. I was an enthusiastic supporter.) The book is illustrated with the author's photographs and line drawings and with reproductions of his distinctive paintings of birds.

G. T. CORLEY SMITH

Handbook of North American Birds Vols 2 \& 3, edited by Ralph S. Palmer. Yale University Press, $£ 19.80$ each vol.

Ducks, Geese and Swans of North America, by Frank C. Bellrose. Stackpole, $\$ 12.95$.

Volume 1 of this major handbook, 'Loons through Flamingos', published in 1962, set a high standard; the two waterfowl volumes, published 14 years later, do not disappoint. They will obviously be compared with Bellrose's book, reviewed below, and with Johnsgard's Waterfowl of North America published in 1975. Of the three Palmer includes the greatest number of species (64) and gives the fullest treatment; he has, also, the most extensive cover of the literature and includes a high proportion of references that are not North American. But while the emphasis in Bellrose is on management techniques, and in Johnsgard on behaviour (descriptions of display and breeding habits owe much to studies of captive birds), Palmer uses a more classically 'museum' approach. Very detailed treatment is given to the section on plumages, while 
geographical variation and subspeciation receive considerable attention. Other aspects fully covered are habitat, distribution, migration, reproduction, survival and food. A great deal of information is provided, far more than in Johnsgard and, in some fields, more than in Bellrose. But the volumes are expensive, and Volume 1 is needed to understand in detail the conventions used in the succeeding ones. The illustrations and maps are good - especially so are some charming paintings of downy young by Colleen Nelson. The books can certainly be recommended to anyone working in the waterfowl field who can afford the outlay.

F. H. Kortright's Ducks, Geese and Swans of North America was published in 1942. and rapidly became a classic. Frank Bellrose's book is a much expanded and up-dated version in which the only obvious 'lifts' from the original are the illustrations. However, the clarity of the writing and the thoroughness of the research have been maintained. The book is aimed principally at wildlife managers who regard wildfowl as a resource, and the emphasis is on surveys, reproductive potential, flyways, the timing of migrations, age and sex ratios, mortality, etc. The more 'purely' biological aspects have not been neglected, and many of the data came from unpublished sources to which Frank Bellrose had access through the US Fish \& Wildlife Service or personal contacts. So a large amount of recent information has been gathered together in text. maps and diagrams, and at a very reasonable price. Low cost presumably accounts for the rather flimsy binding, thin paper and poor printing. It seems a pity, although probably inevitable.

JANET KEAR

\section{Mountain Sheep and Man, by Valerius Geist. Cornell University Press, $£ 8$.}

Geist is a field ecologist of outstanding ability whose particular interest is the evolution of northern ungulates. His recent book describes the background to his well known study of mountain sheep. It provides many fascinating insights into the conditions under which he worked as well as several exciting new explanations of evolutionary trends among ungulates: in particular, I found his exposition of the co-evolution of sharp horns and fighting strategies in mountain goats cogent and convincing. His writing is vigorous and colloquial, and he catches, with considerable sensitivity, the energy, beauty and sadness of the northern wilderness where he worked.

Wildernesses have, however, an unfortunate tendency to produce prophets. In the last chapters of the book, Geist abandons the viewpoint of the field worker for a far more ethereal role. Man, he argues, only developed most of his specifically human characteristics in the middle to late Pleistocene when, for the first time, he became a cooperative hunter of large mammals. Hampered by adaptations from this hunting past ('We shall never escape the inherent biological rules that govern our actions'), modern man has allowed technology to proliferate unchecked to a point where it threatens his continued existence ('Let it continue unchecked, like a cancer, and we shall become its victims - as certainly as the sun will rise'). His solution is simple and drastic: 'From a biologist's viewpoint, the solution entails linking the reproductive efforts of individuals to superior physical and intellectual performance - to escape the gradual randomizing of genetically controlled growth processes shaping the microand macrostructures of our organs and bodies.' . . . . The alternative, embracing an egalitarian philosophy, would inevitably lead to greater diversion (sic) of technology to prop up failing human minds and bodies, to an increased regimentation of the individual's life and to dictatorship by technocrats and machines.'

Geist's arguments concerning primate and human evolution are generally exotic and sometimes erroneous, while his analysis of our current predicament is superficial. For this reason, I would only recommend the book to those who, like mountain sheep, prefer to take a certain amount of salt with their forage.

T. H. CLUTTON-BROCK 